\title{
Multi-Component EPR Spectra of Coals with Different Carbon Content
}

\author{
B. Pilawa ${ }^{a, *}$, A.B. Wiģckowski ${ }^{b}$, R. Pietrzak ${ }^{c}$ \\ AND H. WACHOWSKA ${ }^{c}$ \\ ${ }^{a}$ Institute of Coal Chemistry, Polish Academy of Sciences \\ Sowińskiego 5, 44-121 Gliwice, Poland \\ ${ }^{b}$ Division of Magnetic Resonance Spectroscopy, Institute of Physics \\ Faculty of Physics \& Astronomy, University of Zielona Góra \\ Szafrana 4a, 65-516 Zielona Góra, Poland \\ ${ }^{c}$ Laboratory of Coal Chemistry and Technology, Faculty of Chemistry \\ Adam Mickiewicz University, Grunwaldzka 6, 60-780 Poznań, Poland \\ EPR spectra of lignite "Mequinenza" (Spain) (62.3 wt\% C) and Polish \\ orthocoking coal $(87.8 \mathrm{wt} \% \mathrm{C})$ were compared. The spectra were superposi- \\ tions of broad Gaussian, broad Lorentzian 1, and narrow Lorentzian 3 lines. \\ Concentration of paramagnetic centers - mainly delocalized $\pi$ electrons - \\ responsible for narrow Lorentzian 3 lines increases with increase in carbon \\ content in coal. Coal units with slow and fast spin-lattice relaxation pro- \\ cesses exist in the two studied samples. Slow spin-lattice interactions occur \\ in simple aromatic coal units with broad Gaussian and Lorentzian 1 lines. \\ Fast spin-lattice relaxation processes are characteristic of large aromatic \\ units with narrow Lorentzian 3 lines.
}

PACS numbers: 61.66.Hq, 76.30.Rn

\section{Introduction}

Multi-component structure of EPR spectra of two coals differing in carbon content was numerically analyzed. Spectroscopic studies were performed for lignite ( $62.3 \mathrm{wt} \% \mathrm{C})$ and compared with those obtained for orthocoking coal $(87.8 \mathrm{wt} \% \mathrm{C})$ $[1,2]$. The aim of this work was to characterize properties of paramagnetic centers

*corresponding author; e-mail: pilawa@karboch.gliwice.pl 
in low and high coalificated samples. The number and shape of component lines in the complex EPR spectra were determined. Spin-spin and spin-lattice interactions were studied.

\section{Experimental}

\subsection{Samples}

Coals from the following mines were studied: lignites Mequinenza (Spain) and orthocoking coal Zofiówka (Poland). The samples were ground to $\leq 0.06 \mathrm{~mm}$ in the atmosphere of neutral gas and stored in vacuum and demineralized by the Radmacher and Mohrhauer [3] method using $\mathrm{HCl}$ and HF. After careful washing with warm distilled water the samples were dried to constant mass at $60^{\circ} \mathrm{C}$. The data characterizing the raw and demineralized coal and more preparative details are given elsewhere [4].

\subsection{EPR method}

The EPR spectra of the evacuated $\left(10^{-4}\right.$ Torr $)$ coal samples were measured using an X-band $(9.3 \mathrm{GHz})$ electron paramagnetic resonance spectrometer with magnetic modulation frequency of $100 \mathrm{kHz}$. The microwave frequency was recorded. The EPR spectra were obtained with high attenuation of microwave power of $20 \mathrm{~dB}(\approx 70 \mathrm{~mW})$ to avoid signal saturation.

The number and shape of component lines in the complex EPR spectra were determined. EPR spectra recorded at microwave power $0.7-70 \mathrm{~mW}$ were fitted by different superpositions of Gaussian and Lorentzian lines. The parameters of the best fitted lines were determined. Concentrations of different types of paramagnetic centers in coals were compared. Changes of intensities with microwave power were analyzed.

\section{Results}

Numerical analysis of line shape of EPR spectra of "Mequinenza" (62.3 wt\% C) and "Zofiówka" (87.8 wt\% C [2]) coals indicates their multicomponent character. The EPR spectra are superposition of three components: broad Gaussian, broad Lorentzian 1 and narrow Lorentzian 3 lines. EPR spectra of raw and demineralized lignite and orthocoking coal measured at low microwave power $0.7 \mathrm{~mW}$ are shown in Figs. 1 and 2. EPR spectra of lignite recorded at different microwave powers are presented in Fig. 3. Influence of microwave power on intensities of the analyzed lignite is shown in Fig. 4. Concentrations of paramagnetic centers and parameters of these spectra are presented in Table.

EPR spectrum of demineralized lignite "Mequinenza" was superposition of broad Gaussian $\left(\Delta B_{\mathrm{pp}}=0.69 \mathrm{mT}\right)$, broad Lorentzian $1\left(\Delta B_{\mathrm{pp}}=0.42 \mathrm{mT}\right)$ and narrow Lorentzian $3\left(\Delta B_{\mathrm{pp}}=0.08 \mathrm{mT}\right)$ lines. $g$-factors for Gaussian, Lorentzian 1 , 

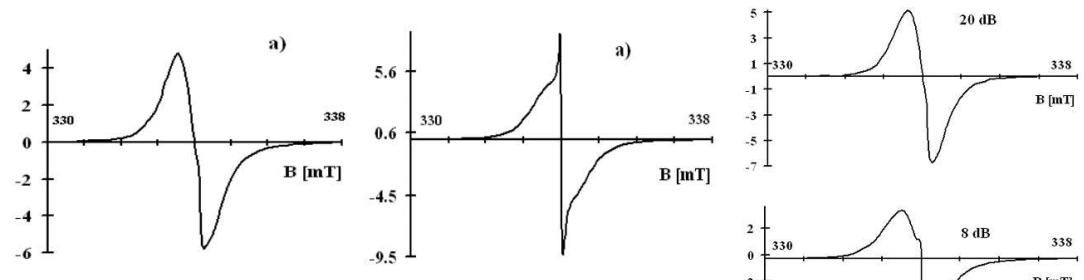

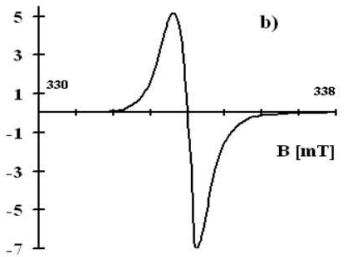

Fig. 1

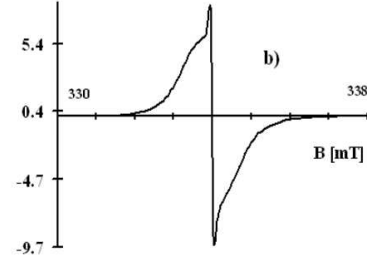

Fig. 2
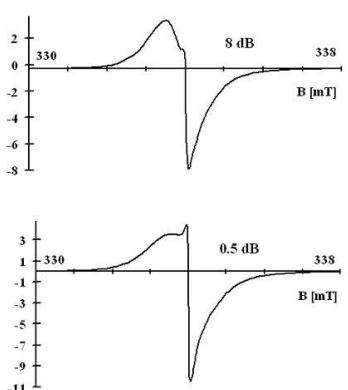

Fig. 3

Fig. 1. EPR spectra of raw (a) and demineralized (b) coal from "Mequinenza" colliery (attenuation $20 \mathrm{~dB}$, microwave power $\approx 0.7 \mathrm{~mW}$ ).

Fig. 2. EPR spectra of raw (a) and demineralized (b) coal from "Zofiówka" colliery (attenuation $20 \mathrm{~dB}$, microwave power $\approx 0.7 \mathrm{~mW}$ ) (according to [2]).

Fig. 3. EPR spectra of demineralized lignite "Mequinenza" recorded with different attenuation.

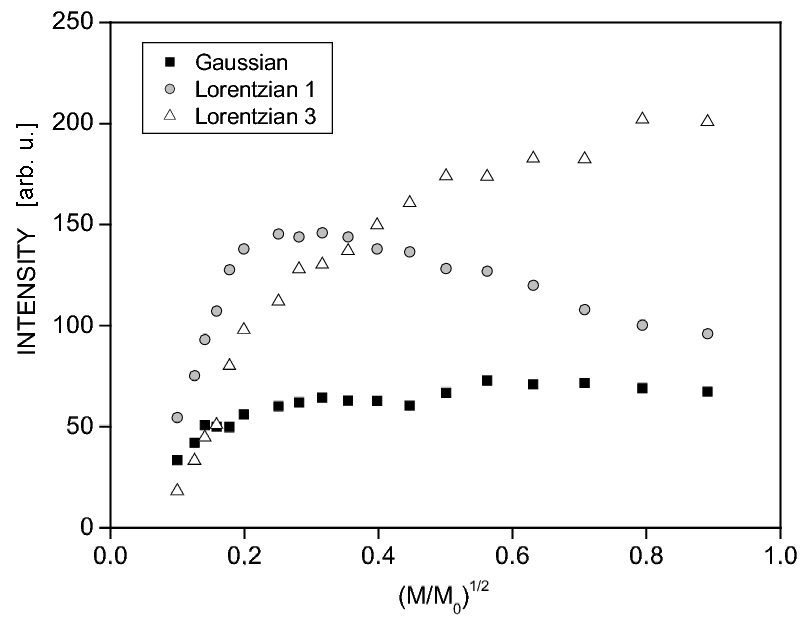

Fig. 4. Influence of microwave power on intensities of EPR lines of demineralized lignite "Mequinenza". $M-$ microwave power used during the measurement, $M_{0}-$ total microwave power produced by klystron $(70 \mathrm{~mW})$.

and Lorentzian 3 lines were 2.0045, 2.0038, 2.0032, respectively. The high $g$-factor of Gaussian line results from localization of unpaired electrons on sulphur atom. Concentrations of paramagnetic centers responsible for Gaussian, Lorentzian 1, and Lorentzian 3 were $1.1 \times 10^{18}, 1.9 \times 10^{18}, 0.03 \times 10^{18} \mathrm{spin} / \mathrm{g}$, respectively. 


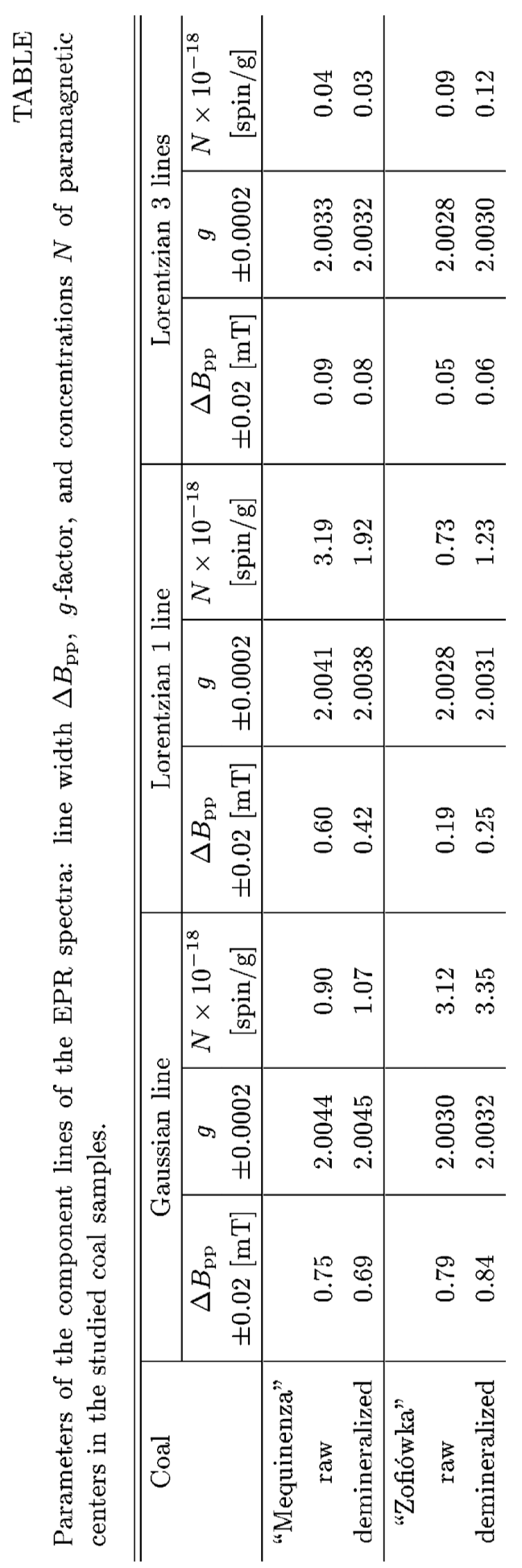


Broad Gaussian $\left(\Delta B_{\mathrm{pp}}=0.84 \mathrm{mT}\right)$, broad Lorentzian $1\left(\Delta B_{\mathrm{pp}}=0.25 \mathrm{mT}\right)$, and narrow Lorentzian $3\left(\Delta B_{\mathrm{pp}}=0.06 \mathrm{mT}\right)$ lines were measured in EPR spectrum of demineralized orthocoking coal. $g$-values of the individual lines for orthocoking coal (Gaussian: 2.0032, Lorentzian 1: 2.0031, Lorentzian 3: 2.0030) were lower than for corresponding EPR lines of lignite. The lower contents of heteroatoms $(\mathrm{S}, \mathrm{N}$, and $\mathrm{O})$ in coals with higher carbon contents explain this correlation. Concentrations of paramagnetic centers with Gaussian, Lorentzian 1, and Lorentzian 3 lines were $3.3 \times 10^{18}, 1.2 \times 10^{18}$, and $0.12 \times 10^{18} \mathrm{spin} / \mathrm{g}$, respectively.

Paramagnetic centers of simple aromatic units in coals are responsible for broad Gaussian and Lorentzian 1 lines [1, 2, 5-7]. Paramagnetic centers, mainly delocalized $\pi$ electrons, of multi-ring aromatic units are responsible for narrow (Lorentzian 3) lines [1, 2, 5-7]. Contents of paramagnetic centers of large aromatic structures with narrow Lorentzian 3 lines increased considerably in highly metamorphosed coal $(87.8 \mathrm{wt} \% \mathrm{C})$ relatively to lignite $(62.3 \mathrm{wt} \% \mathrm{C})$.

Broad EPR lines of both the studied coals saturate at lower microwave powers than the narrow lines (Fig. 3). Fast spin-lattice relaxation processes exist in multi-ring aromatic coal units.

\section{Conclusions}

Multi-component structure of EPR spectra of coals depends on carbon contents in the samples.

Concentration of paramagnetic centers of multi-ring aromatic units increases for higher metamorphosed coal samples.

Broad EPR lines of both the studied coals saturate at lower microwave powers than the narrow lines. Fast spin-lattice relaxation processes exist in multi-ring aromatic coal units.

\section{References}

[1] B. Pilawa, A.B. Więckowski, R. Pietrzak, H. Wachowska, Mol. Phys. Rep. 34, 127 (2001).

[2] B. Pilawa, A.B. Więckowski, R. Pietrzak, H. Wachowska, Fuel 81, 1925 (2002).

[3] W. Radmacher, P. Mohrhauer, Brennstoff-Chemie 37, 353 (1956).

[4] R. Pietrzak, H. Wachowska, Fuel 82, 705 (2003).

[5] B. Pilawa, A.B. Więckowski, B. Trzebicka, Mol. Phys. Rep. 4, 245 (1994).

[6] B. Pilawa, A.B. Więckowski, B. Trzebicka, Radiat. Phys. Chem. 45, 899 (1995).

[7] B. Pilawa, B. Trzebicka, A.B. Więckowski, Fuel 70, 1109 (1991). 